\title{
A Framework of Evidence-Based Decision-Making in Health System Management: Applying Best-Fit Framework Synthesis
}

Tahereh Shafaghat

Shiraz University of Medical Sciences

Peivand Bastani ( $\sim$ bastanip@sums.ac.ir)

Shiraz University of Medical Sciences https://orcid.org/0000-0002-0412-0267

Mohammad Hasan Imani Nasab

Lorestan University of Medical Sciences

Mohammad Amin Bahrami

Shiraz University of Medical Sciences

Zahra Kavosi

Shiraz University of Medical Sciences

Mahsa Roozrokh Arshadi Montazer

Shiraz University of Medical Sciences

Mohammad Kazem Rahimi Zarchi

Shahid Sadoughi University of Medical Sciences and Health Services Yazd Research and Clinical Centre for Infertility

Research article

Keywords: evidence-based decision-making, management, health system, best-fit framework synthesis

Posted Date: April 27th, 2020

DOI: https://doi.org/10.21203/rs.3.rs-24295/v1

License: (c) (i) This work is licensed under a Creative Commons Attribution 4.0 International License. Read Full License 


\section{Abstract}

Background: Scientific evidence is the basis for improving public health; decision-making without sufficient attention to evidence may lead to unpleasant consequences. In recent years, efforts have been made to create more comprehensive guidelines for evidence-based decision-making (EBDM), thus the purpose of the present study was developing a framework for EBDM to make the best decisions concerning to scare resources and too many needs.

Methods: The present basic-applied research was a secondary study carried out using qualitative research method in 2019. A Systematic Scoping Review (SSR) was done for the comprehensive review of the existing published studies in this area. This method, according to Arksey and O'Malley approach, consists of five main stages and one optional stage.

Results: Based on the SSR, 3751 studies from 7 databases were found, and due to the full-text screening of the studies, 30 final studies were selected for extracting the components and steps of EBDM in Health System Management (HSM). After collecting, synthesizing, and categorizing key information, the framework of EBDM in HSM is developed in the form of four general scopes of inquiring, inspecting, implementing and integrating, which includes 10 main steps and 56 sub-steps.

Conclusions: The present framework tries to present a sequential systematic map to achieve evidence-based decision and policy making specially for under developed and developing countries which mostly suffer from applying update and applied evidences in their decision-making process. At the same time, it seems that the present framework tries to synthesize and integrate the fragmented elements of the other models and in this way can be tested by developed countries to improve their EBDM cycle.

\section{Background}

On the international level, there is a growing interest in increasing the use of research evidence in public health policy-making and related actions (1,2). Public health systems are diverse and complex, and public health policymakers face challenging tasks in developing and implementing policies and programs that are required be efficient in the health system or at the community level $(1,3)$. To carry these responsibilities in an effective way, scientific evidence needs to be incorporated into the design and decision-making process (3-5). Also, health systems are always plagued with the lack of sufficient resources; therefore, EBDM is essential to optimize costs and prevent wastes (6). Scientific evidences are the basis for improving public health. If health care managers and policymakers ignore evidence of the root causes of problems or effective solutions to these problems, they allocate expensive resources to inappropriate programs and put them at risk of wasting. The direct consequence of ignoring evidence is poorer health for the community (7). The large number of people affected by public health policies also increases the need for sound decision-making. Good intentions and justified hypotheses cannot alone be the basis for the decision-making of public programs that have a significant impact on others' lives (8).

Some health interventions implemented solely in the belief that they are beneficial to the community are ineffective or harmful and cause public resources to be wasted. In contrast, some cost-effective interventions are either neglected or slowly implemented (9). Reliable evidence suggests that health systems often fail to exploit research evidence properly, leading to inefficiencies, reduced quality and quantity of citizens lives, and a decline in productivity (10). Using the evidence of health systems in policymaking is a problem that many developed and developing countries are facing nowadays. This is especially important in countries where their health systems are in a rapid transition, like many countries in the eastern Mediterranean region, however (11). In 2012, a study in EU countries showed that health policymakers rarely had necessary structures, processes, and tools to exploit research evidence in the policy cycle (12).

Hence, evidence-based policymaking in developing countries can have more significant impacts. Better use of evidence in developing countries can help save lives, reduce poverty, and improve performance $(13,14)$. Where resources are scarce, policymakers' awareness of research evidence becomes more important to ensure informed use of scarce resources (15). Low and middle income countries have fewer resources to deal with health issues and need more quality evidence for efficient use of these scarce resources (7). EBDM, however, always encounters with the most pressing needs and the least capacity dilemma, so developing countries have less capacity than developed countries to adopt this approach (14).

Decision-making in health sector without sufficient attention to evidence may lead to the following consequences: health services are not always accessible to those most in need, health indicators are not improved as they should be, and many countries are unable to achieve the MDGs. Besides, decisions without sufficient attention to evidence may also lead to a lack of effectiveness, efficiency, and fairness in health systems (16). Instead, the advantages of EBDM include adopting cost-effective interventions, making optimal use of limited resources, increasing customer satisfaction, minimizing harm to individuals and society, achieving better health outcomes for individuals and society $(17,18)$, and increasing the effectiveness and efficiency of public health programs (19).

In recent years, efforts have been made to create more comprehensive guidelines for EBDM in healthcare settings (20). Stakeholders are significantly interested in supporting evidence-based projects that can quickly prioritize funding allocated to health sectors ensuring the necessary use of their financial resources effectively (21-23). It is unlikely that the implementation of EBDM in HSM will follow the evidence-based medicine model. Also, individuals cannot use research findings only because they require organizational support and resources $(17,24)$. On the other hand, the capacity of organizations to facilitate evidence utilization is complex and not well understood (24); besides, EBDM process is not usually institutionalized within the organizational processes (17). A study in 2005 found that around the world, few organizations support the use of research evidence in health-related decisions (25). Weis et al. (2012) also reported there is insufficient information on EBDM in local health sectors (19). In general, it can be said that relatively few organizations hold themselves accountable for using research evidence in developing health policies (26). Therefore, because of the significance of making the best decisions and allocating the scarce resources to achieve the main goals of the organizations and at the same time, improving the personal, institutional and organizational capacities to overcome the existing obstacles and problems effectively, this study aimed to synthesize a framework for EBDM for developing its application in the health organizations. 


\section{Methods}

The present basic-applied study was a secondary research carried out using the qualitative method in 2019. The purpose of the study was to develop a comprehensive framework for EBDM in HSM. Thus, a SSR was conducted for the comprehensive review of the existing literatures in this area. This kind of review was applied because of its comprehensive, systematic and quantitative approach. The distinguishing point of a scoping review over other comprehensive reviews is both the greater scope of searching, as well as the qualitative textual analysis, which helps finding the EBDM components accurately and creating a deeper understanding of the influencing factors on it $(28,29)$. According to Arksey and O'Malley approach, a SSR consists of five main stages and one optional stage as follows: identifying the research question, identifying relevant studies, screening and selecting the studies, synthesizing and categorizing the data, summarizing and reporting, and verifying and validating the results using the expert panel (optional)(28-30). These stages are discussed as follows: $\backslash$

1. Identifying the research question: The main research question was "what are the components of EBDM in HSM and its associated models in existing studies?"

2. Identifying relevant studies: In this step, the researchers searched for published studies on EBDM in HSM in different scientific databases with relevant keywords and constraints as inclusion and exclusion criteria from 2000 to 2018 (Table 1).

Table 1: Search strategy for the review

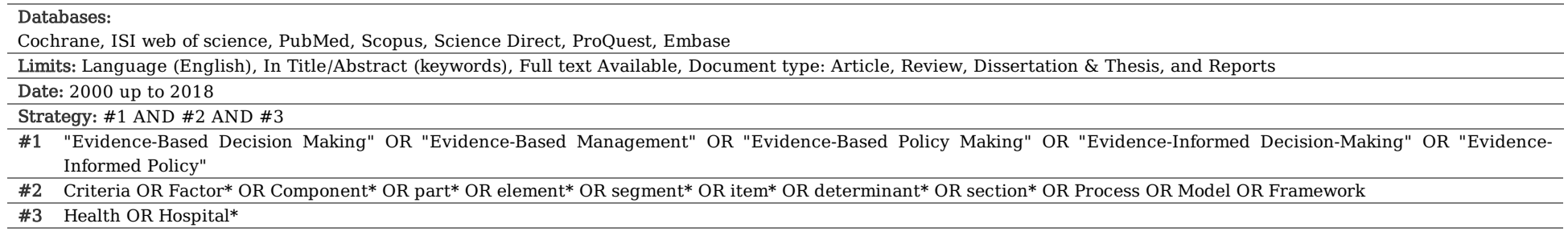

3. Screening and selecting the studies: Inclusion criteria included studies that identify the components or develop a model or framework of EBDM in HSM, in the form of original or review articles or dissertations, which were published in English and had a full text. The exclusion criteria were also determined to exclude studies that lacked full-text or non-English language, as well as articles from the book review, opinion articles, and commentaries that lacked a specific framework for reviewing the study. During the search phase of the study, it was attempted, as far as possible, to access studies that were not included in the search process or gray literature by reviewing the references lists of the retrieved studies or by contacting the authors of the articles or experts and querying them, as well as manually searching related sites. After searching the studies from all databases and removing duplicates, the studies were independently reviewed and screened by two members of the research team in three phases by title, abstract and then the full text of the articles. At each stage of the study, the final decision to enter the study to the next stage was based on agreement and, if disagreed, the opinion of the third person from the research team was asked. Since there is usually no need to evaluate the quality of the retrieved studies in the scoping review (28), the quality of the obtained studies was not investigated in this study.

Mendeley software was used to systematically search and screen relevant studies. The data for the included studies were extracted based on the study questions and accordingly, a form of the studies profile including author's name, publication year, country, study title, type of study and its conditions in Excel software was prepared.

4. Synthesizing and categorizing of data: The Best-Fit Framework (BFF) synthesis was used for data analysis and synthesis. One of the distinctive features of the BFF method is the creation of new ways of identifying theories systematically with the rapid synthesis of evidence (31,32). The BFF approach is appropriate to create the conceptual models to describe or express the decisions and behaviors of individuals and groups in a particular domain (32). This framework is distinct from other methods of qualitative evidence synthesis because it employs a systematic approach to create an initial framework for synthesis based on existing frameworks, models, or theories (32).

The BFF synthesis first requires identifying an appropriate conceptual framework, theory or model for specific behaviors. This initial framework can be derived from a relatively well-known model in the target field, or be formed by the integration of several existing models. The initial framework is then reduced to its key components that have shaped its concepts. Thereafter, the relationships between framework concepts and components are created or recreated based on evidence from selected studies in a SSR (32). In fact, the initial framework considers as the basis and it can be rebuilt, extended, or reduced based on its dimensions (31). New concepts also emerge based on the researchers' interpretation of the evidence and ongoing comparisons of these concepts across studies (32). The initial framework changes in response to the evidence reported in the selected studies on the systematic review; therefore, the final product is a revised framework that can include both the basic and the modified and new components that were not anticipated in the initial framework (33). Accordingly, a new framework or theory emerges regarding the particular behavior or tendency in a population or situation (32).

Therefore, according to the aforementioned discussion, the components of EBDM in HSM as well as models available in this regard were extracted as semantic units (conceptual codes) from the results sections of the articles and, if possible, from the discussion sections. After compiling and categorizing the codes, themes, and sub-themes, we compare the existing models and try to find a model that fits the best. The authors identified six studies with related models or frameworks that appeared to be well suited to the proposed population, conditions, behavior, as well as the inclusion criteria. The options we had included either overriding one of the models (by choosing one particular model and rejecting the others as desired), using two or more models in combination, or creating an initial framework based on all 6 previous studies. In this respect, the third option was selected. The reason for this choice was the absence of 
any practical justification for choosing one model over the others. Carroll et al. (2013) also used the same approach in their study to use the BFF synthesis (32).

The present synthesis approach has been both positivist and interpretative; it provides the simultaneous use of the well-known strengths of both framework analysis and content analysis (34). Data analysis was initially implicit and inductive, without considering the other models presented in the studies. After creating the initial framework based on existing models and extracting all the concepts from all the studies, the same concepts were classified explicitly and deductively using the initial framework concepts. The only data that were not compatible with the basic framework were not needed to be reinterpreted using the inductive content analysis method (32). So, the articles were read multiple times for data immersion. At this stage, conceptual codes were categorized according to semantic similarities and differences, and then the codes extracted from each of the studies were compared with each other and categorized as themes and sub-themes in the modified conceptual framework.

5. Summarizing and reporting: Finally, an EBDM framework for HSM has been recreated based on the analyzing and resynthesizing of all previous models. The potential value of the BFF synthesis is rapid detection, especially for synthesizing qualitative evidence to answer urgent policy questions (33). This is due to the simultaneous use of the benefits of content analysis and framework analysis (32).

\section{Ethical considerations}

To prevent bias, all stages of the study such as screening, data extraction, and data analysis were carried out by two individuals.

\section{Results}

In the initial search in seven electronic databases based on the SSR, 3751 studies were found. After removing duplicates, 2051 studies were assessed based on their titles. According to the abstract screening of the 1041 studies that remained after removing the irrelevant titles, 384 studies were selected and entered to the full-text screening phase. Due to full-text screening of the studies, 30 final studies were selected for extracting the components and steps of EBDM in HSM (Fig 1). The features of these studies were summarized in the appendix: Table 2 (see supplementary data).

Table 2: Summary of characteristics of included studies 


\begin{tabular}{|c|c|c|c|c|c|}
\hline & $\begin{array}{l}\text { First Author } \\
\text { (Year) }\end{array}$ & Country & Study Title & Study Design & Setting \\
\hline 1 & $\begin{array}{l}\text { Paul R. } \\
\text { Falzer } \\
(2009)\end{array}$ & USA & A Conditional Model of Evidence-Based Decision Making & $\begin{array}{l}64 \text { case vignettes (with fillers) } \\
\text { constructed from a fully balanced set } \\
\text { of five factors }\end{array}$ & $\begin{array}{l}21 \text { residents at one psychiatry } \\
\text { training program }\end{array}$ \\
\hline 2 & $\begin{array}{l}\text { Zhanming } \\
\text { Liang } \\
(2012)\end{array}$ & Australia & $\begin{array}{l}\text { A framework to improve evidence-informed decision- } \\
\text { making in health service management }\end{array}$ & review of academic literature & 46 studies were included \\
\hline 3 & $\begin{array}{l}\text { Yan Li } \\
(2015)\end{array}$ & $\begin{array}{l}\text { New York, } \\
\text { USA }\end{array}$ & $\begin{array}{l}\text { Advancing the Use of Evidence-Based Decision-Making in } \\
\text { Local Health Departments With Systems Science } \\
\text { Methodologies }\end{array}$ & $\begin{array}{l}\text { Small group interviews and focus } \\
\text { groups }\end{array}$ & $\begin{array}{l}\text { participants from } 31 \text { LHDs (Local } \\
\text { health departments) who had } \\
\text { decision-making responsibilities. }\end{array}$ \\
\hline 4 & $\begin{array}{l}\text { Randi W. } \\
\text { Aas (2012) }\end{array}$ & Norway & $\begin{array}{l}\text { Challenging Evidence-based Decision-making: A } \\
\text { Hypothetical Case Study about Return to Work }\end{array}$ & A hypothetical case study & --- \\
\hline 5 & $\begin{array}{l}\text { Melanie } \\
\text { Kazman } \\
\text { Kohn }(2011)\end{array}$ & --- & $\begin{array}{l}\text { Evidence-based decision making in health care setting: } \\
\text { from theory to practice }\end{array}$ & Essay & --- \\
\hline 6 & $\begin{array}{l}\text { Mark J. } \\
\text { Dobrow } \\
(2004)\end{array}$ & $-\cdots$ & Evidence-based health policy: context and utilization & --- & $-\cdots$ \\
\hline 7 & $\begin{array}{l}\text { Megan Ward } \\
(2011)\end{array}$ & Canada & $\begin{array}{l}\text { Evidence-informed decision making in a public health } \\
\text { setting }\end{array}$ & Literature review & $\begin{array}{l}\text { PubMed/ Tools published on the web } \\
\text { sites of national organizations tasked } \\
\text { with developing guidelines or other } \\
\text { products }\end{array}$ \\
\hline 8 & $\begin{array}{l}\text { Collette D. } \\
\text { Sosnowy } \\
(2013)\end{array}$ & $\begin{array}{l}\text { New York, } \\
\text { USA }\end{array}$ & $\begin{array}{l}\text { Factors Affecting Evidence-Based Decision Making in Local } \\
\text { Health Departments }\end{array}$ & Interview, focus groups & 20 individual \\
\hline 9 & $\begin{array}{l}\text { François } \\
\text { Champagne } \\
(2014)\end{array}$ & $\begin{array}{l}\text { Alberta, } \\
\text { Saskatchewan, } \\
\text { Quebec and } \\
\text { Nova Scotia }\end{array}$ & $\begin{array}{l}\text { Organizational impact of evidence-informed decision } \\
\text { making training initiatives: a case study comparison of two } \\
\text { approaches }\end{array}$ & $\begin{array}{l}\text { 1.theory-driven evaluation } \\
\text { 2.analyzed six case studies } \\
\text { 3. analysis relied on a triple } \\
\text { comparative design } \\
\text { /interviewed site visits }\end{array}$ & 84 people \\
\hline 10 & $\begin{array}{l}\text { Wilza Carla } \\
\text { Spiri (2017) }\end{array}$ & São Paulo & $\begin{array}{l}\text { Perception of Nursing Middle Managers about the } \\
\text { Evidence-Based Management }\end{array}$ & $\begin{array}{l}\text { Case Study/ individual structured } \\
\text { interview }\end{array}$ & 15 middle managers \\
\hline 11 & $\begin{array}{l}\text { Ross C. } \\
\text { Brownson } \\
(2014)\end{array}$ & $\begin{array}{l}\text { Washington } \\
\text { University }\end{array}$ & $\begin{array}{l}\text { Practice-Research Partnerships and Mentoring to Foster } \\
\text { Evidence-Based Decision Making }\end{array}$ & Essay & --- \\
\hline 12 & $\begin{array}{l}\text { Maureen } \\
\text { Dobbins } \\
(2007)\end{array}$ & Ontario & $\begin{array}{l}\text { Public Health Decision-Makers' informational Needs and } \\
\text { Preferences for Receiving Research Evidence }\end{array}$ & $\begin{array}{l}\text { A fundamental qualitative descriptive } \\
\text { design/ semi-structured interviews }\end{array}$ & $\begin{array}{l}16 \text { respondents public } \\
\text { health decision-makers }\end{array}$ \\
\hline 13 & $\begin{array}{l}\text { Katherine A. } \\
\text { Stamatakis } \\
(2017)\end{array}$ & USA & $\begin{array}{l}\text { Results from a psychometric assessment of a new tool for } \\
\text { measuring evidence-based decision making in public } \\
\text { health organizations }\end{array}$ & Quantitative/ questionnaire & 879 \\
\hline 14 & $\begin{array}{l}\text { Claire Harris } \\
(2017)\end{array}$ & Australia & $\begin{array}{l}\text { Sustainability in Health care by Allocating Resources } \\
\text { Effectively (SHARE) 7: supporting staff in evidence-based } \\
\text { decision-making, implementation and evaluation in a local } \\
\text { healthcare setting }\end{array}$ & $\begin{array}{l}\text { Literature reviews, surveys, } \\
\text { interviews, consultation and } \\
\text { workshops }\end{array}$ & $-\cdots$ \\
\hline 15 & $\begin{array}{l}\text { Claire Harris } \\
(2018)\end{array}$ & Australia & $\begin{array}{l}\text { Sustainability in Health care by Allocating Resources } \\
\text { Effectively (SHARE) 8: developing, implementing and } \\
\text { evaluating an evidence dissemination service in a local } \\
\text { healthcare setting }\end{array}$ & $\begin{array}{l}\text { Mixed methods including: literature } \\
\text { review, surveys, interviews, } \\
\text { workshops, audits, document analysis } \\
\text { and action research }\end{array}$ & $-\cdots$ \\
\hline 16 & $\begin{array}{l}\text { Rebecca } \\
\text { Armstrong } \\
(2014)\end{array}$ & $\begin{array}{l}\text { Victoria, } \\
\text { Australia }\end{array}$ & $\begin{array}{l}\text { Understanding evidence: a statewide survey to explore } \\
\text { evidence-informed public health decision-making in a local } \\
\text { government setting }\end{array}$ & $\begin{array}{l}\text { mixed-method/ Questionnaire and } \\
\text { Interview }\end{array}$ & $\begin{array}{l}135 \text { Questionnaire responses and } 13 \\
\text { interviews }\end{array}$ \\
\hline 17 & $\begin{array}{l}\text { Ali Janati } \\
(2018)\end{array}$ & Iran & $\begin{array}{l}\text { An Evidence-Based Framework for Evidence-Based } \\
\text { Management in Healthcare Organizations: A Delphi Study }\end{array}$ & $\begin{array}{l}\text { two-round Delphi survey } \\
\text { systematic review and a series of } \\
\text { semi-structured interviews, } \\
\text { questionnaire }\end{array}$ & $\begin{array}{l}\text { in first round }=45, \\
\text { in second round }=21\end{array}$ \\
\hline 18 & $\begin{array}{l}\text { Prue F. E. } \\
\text { Addison } \\
(2016)\end{array}$ & $\begin{array}{l}\text { Australia and } \\
\text { New Zealand }\end{array}$ & $\begin{array}{l}\text { Conservation practitioners' perspectives on decision } \\
\text { triggers for evidence-based management }\end{array}$ & workshop & 15 \\
\hline 19 & $\begin{array}{l}\text { Mohsen } \\
\text { Saberi } \\
\text { Isfeedvajani } \\
(2018)\end{array}$ & Iran & $\begin{array}{l}\text { Evidence-Based Management and its Application in the } \\
\text { Hospital Management Process }\end{array}$ & Letter & ---- \\
\hline 20 & $\begin{array}{l}\text { April L. } \\
\text { Wright } \\
(2016)\end{array}$ & Australia & $\begin{array}{l}\text { Evidence-based Management in Practice: Opening up the } \\
\text { Decision Process, Decision-maker and Context } \\
\text { Evidence-Based }\end{array}$ & Case study /Qualitative/ interview & $\begin{array}{l}24 \text { emergency physicians and } \\
\text { registrars, four hospital executives } \\
\text { and one nurse }\end{array}$ \\
\hline 21 & $\begin{array}{l}\text { Damian } \\
\text { Eisenghower } \\
\text { Greaves } \\
(2017)\end{array}$ & $\begin{array}{l}\text { Caribbean } \\
\text { island }\end{array}$ & $\begin{array}{l}\text { Evidence-based management of Caribbean health systems: } \\
\text { barriers and opportunities }\end{array}$ & $\begin{array}{l}\text { semi-structured, in-depth interviews } \\
\text { comprising }\end{array}$ & 20 senior managers/leaders \\
\hline 22 & $\begin{array}{l}\text { Hayfaa A. } \\
\text { Wahabi } \\
(2015)\end{array}$ & Riyadh & $\begin{array}{l}\text { Evidence-Based Decision Making in Public Health: } \\
\text { Capacity Building for Public Health Students at King Saud } \\
\text { University in Riya }\end{array}$ & questionnaire & 33 student \\
\hline 23 & $\begin{array}{l}\text { Ross C. } \\
\text { Brownson } \\
(1999)\end{array}$ & Missouri, US & Evidence-Based Decision Making in Public Health & $\begin{array}{l}\text { Developing the framework through } \\
\text { work-team and pilot testing during a } \\
\text { four-day course }\end{array}$ & $\begin{array}{l}12 \text { mid-level manager in Missouri } \\
\text { department of health }\end{array}$ \\
\hline 24 & $\begin{array}{l}\text { Ross C. } \\
\text { Brownson } \\
(2009)\end{array}$ & US & $\begin{array}{l}\text { Evidence-Based Public Health: A Fundamental Concept for } \\
\text { Public Health Practice }\end{array}$ & Descriptive/ review & --- \\
\hline 25 & $\begin{array}{l}\text { Neal D. } \\
\text { Kohatsu } \\
(2004)\end{array}$ & Iowa & $\begin{array}{l}\text { Evidence-Based Public Health } \\
\text { An Evolving Concept }\end{array}$ & Review & ---- \\
\hline
\end{tabular}


26 Marguerite Pappaioanou (2003)

27 Jennifer Yost (2014)
USA

Ontario

Canada
Strengthening capacity in developing countries for evidence-based public health: the data for decision-making project

Tools to support evidence-informed public health decision a case study design/ Quantitative and making experimental qualitative data
Bolivia, Cameroon, Mexico, and the Philippines' health system

A purposive sample of senior management and public health professionals

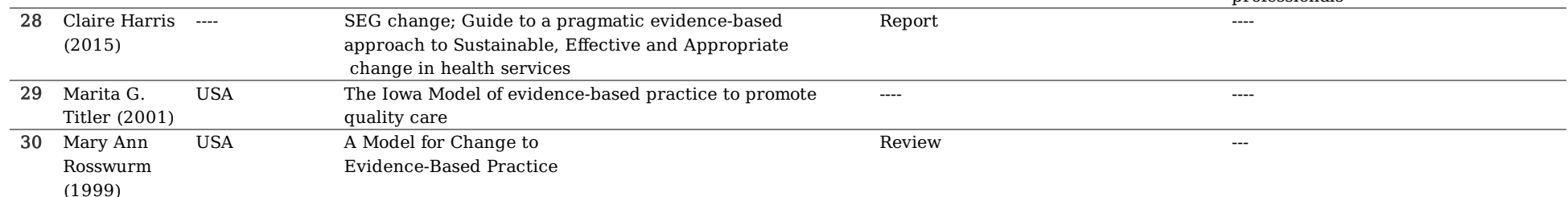

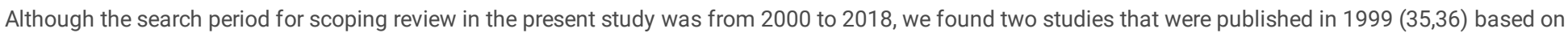

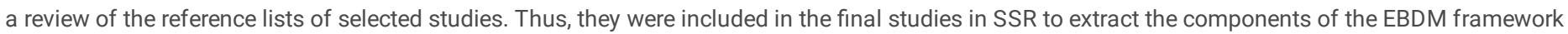

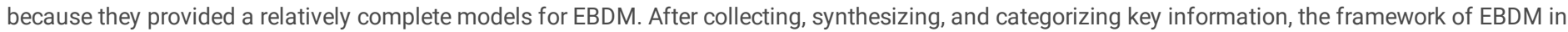

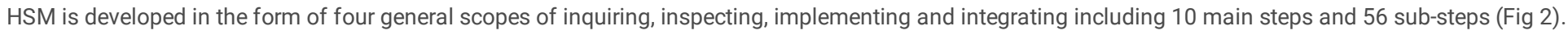
The sub-steps related to each main step are explained in detail in appendix, Table 3 (see supplementary data).

\section{Table 3: The steps and sub-steps of evidence based decision making framework}


1. Prioritization of the problem (26)

1. Surveying the results of previous interventions $(2,4)$

1. Acquisition of experts' opinions*

1. Determining Information gaps (26)

Quantifying the issue and Developing a statement $(4,22-24)$

1. Developing the conceptual model for the issue $(2,7,20,27)$

1. Determining data resources:

- Surveillance data (23) or Clinical problems data (29),

- Process improvement or Risk-management data (29),

- Internal/external benchmarking data (29)

- Financial data (29),

- National agencies or organizational standards and guidelines (29),

- New researches and other literature (29)

- Experts' opinions/experiment (2,

1. Collecting outcomes indicators $(26,30)$

1. Defining the main statement of issues*

Capacity Building* and Setting objectives
1. Understanding the context $(2,5)$ and Building an Evidence-Based Culture $(2,19)$

1. Forming the Team (29)

1. Gaining Leadership Support \& Commitment $(2,13,14,28)$

1. Setting objectives $(5,18,26)$

1. Identifying the capabilities required by employees and their skills weaknesses $(4,13,26,28)$

1. Training $(14,26)$

1. Developing the necessary infrastructures* and structures (28) like Improving health information systems (26)

1. Assigning a Mandate (20)

1. Determining Incentives $(2,13)$

Evidence acquisition and integration $(4-7,9,10,12-14,17,19-25,27-30)$

1. Developing an Efficient Search Strategy $(2,27)$

1. finding the sources for seeking the evidence (13-16, 27, 29, 30) according to 6S Pyramid (27):

- Scientific literature $(4,7)$

- Meta-analysis (23) or meta-synthesis*,

- Rapid Reviews (27),

- Other types of evidence (case-report, expert opinion, scientific principles, theory (29), Expert panels (23), Patient's experience (4), Professional expertise (4), Consultation (16), Risk assessments (23), Economic data (23))

1. Keeping Track of Search Results: A Flowchart (27)

1. (If necessary) Designing to* conduct a research (29)

Inspecting Evidence Appraising $(2,4,5,7,9,12,14,17,25,27,29)$

1. Sourcing the evidence (2) using* Library services and RefWorks (7)

1. Removing duplications (28)

1. Appraising and selecting the evidences according to appropriate appraisal tools/methods*: 
2. AGREE II Instrument (27),

3. AMSTAR Tool (27),

4. Critical Appraisal Skills Programme (CASP) Tools (27),

5. Scottish Intercollegiate Guidelines Network (27),

6. Quality Assessment Tool for Quantitative Studies (27),

7. Benefits \& risks, feasibility, applicability and transferability data $(2,7,14,27,30)$

1. Invoking a rejection threshold for including the evidences (1)

Analysis, synthesis and Interpretation of

data $(1-3,6-8,10,12,14,21,26,27,29,1$. Data Extraction for Systematic Reviews (27)

30)

1. Discarding mismatched alternatives (1)

1. Project development and administration (14) with data capture, data entry and analysis (14)

1. analyze and Synthesis* (7) according to:

2. Evidence format (2)

3. Style of presentation (2)

4. Accessibility (2)

5. Validity (2)

6. Context sensitivity (2)

7. Applicability (2)

8. Timeliness (2)

1. Determining potential features (scope, components, knowledge brokers, target audience, methods) (15)

1. Translation of data into user friendly formats (14)/ Use* Knowledge Translation Planning Tool (27)

Implementing Developing Evidence- Based Alternatives
$(1,3,5,7-9,11,16,17,20-28,30)$

1. Engaging community and Stakeholders (customers*) $(3,8,11,16,20,28,30)$ and Participatory Decision Making $(13,28)$

1. Developing program theory/logic (15)

1. Defining proposed changes (30)

1. Identifying needed resources (30)

1. Planning implementation and evaluation process and strategies $(7,15,30)$ /design EBP guideline(s) (29)

1. Defining outcomes to be achieved $(29,30)$ and develop indicators $(18,21,30)$

Pilot Implementation of selected alternatives

$(2,4,6,7,9,11,12,15,17-20,22-24$,

$26-28,30)$

1. Document and investigate the change process in an action research approach (28)
1. Training the trainers and target audience and [staff empowerment according to the specific]* needs assessments (26)

1. Resources allocation (26)

1. Pre-implementation (13) and pilot change in practice $(15,29,30)$

1. Assessing barriers and enablers for implementation (15)

1. Developing recommendations (7) and Reporting template (7)

1. Modifying the practice guidance (29)

1. Collecting baseline data (15) and Measuring at baseline mid-project and one-year post-project (26)

1. Evaluating processes and outcomes $(15,30,29)$ and revise (15)

1. Deciding to adapt, adopt, or reject practice change (30)

1. Assessing factors for success and sustainability (15)

1. Checking the program checklist (27) [and if necessary*] modifying the assessment criteria (1) 
Integrate and maintain change in practice $(2,30)$
1. Making decisions based on the best available scientific and rigorous program evaluation evidence (11)

1. Disseminating evidence results to decision makers $(2,3,14,23,29) /[$ making sure that*] Essential information conveyed effectively to target audiences/stakeholders $(26,30)$

1. Integrating change into standards of practice $(15,28-30)$ or discontinue program or policy (23)

1. Presenting staff in-service education on change in practice (30)

1. Thoughts for future and adaptions (15)/ Feedback and feedforward to evidence based decision making model*

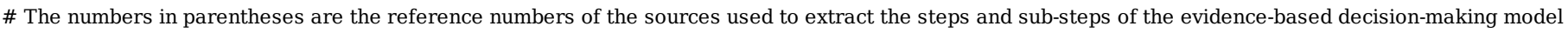
according to table 2 .

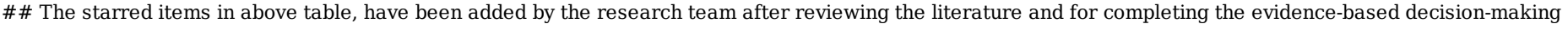
process.

\section{Discussion}

The present study indicates a framework of EBDM in HSM; in this regard, after a SSR of existing studies, based on the most complete models and frameworks presented and published so far, a comprehensive framework of EBDM in HSM is provided using the BFF approach. The BFF synthesis has this potential value for systematic reviewers because they no longer need to review heavy texts, consultations, or expertise in supposed subject to create a basic framework before starting their systematic review. That is, based on the review itself, they can select a suitable baseline model and extend the analysis (31).

Based on the present findings, most of the previous studies only referred to some part of the components and steps of the EBDM in HSM and neglected the other parts or they were not sufficiently comprehensive (37-46). However, the findings of each previous study completed some parts of the framework which presented in this study. Among the studies that have provided a more complete model than the other studies, are the studies by Brownson (1999), Rosswurm (1999), Brownson (2009), Yost (2014), Wahabi (2015), and Janati (2018) $(3,4,35,47-49)$. It should be noted that the combination of these six studies has been used as the initial framework for the best-fit synthesis.

Likewise, the models presented by Brownson (1999), Brownson (2009), Wahabi (2015), and Janati (2018) were only limited to the six or seven key steps of the EBDM process, and they did not mention the details required for each of the steps, too $(3,4,48,49)$. Also, the models presented in the study of Rosswurm $(1999)$ and Janati (2018) were linear, and the relationships between the EBDM components were not well considered $(35,49)$; however, the model presented in this study is recursive. Also, in Yost study (2014), despite the 7 main steps of EBDM and some details of each of the steps, the framework presented was not schematically drawn and therefore the relationships between steps and sub-steps were not clear (47).

In the present study, the framework of EBDM in HSM is developed in the form of four general scopes of inquiring, inspecting, implementing and integrating including 10 main steps and 56 sub-steps. These scopes are discussed as follows:

Inquiring

In the first step, "situation analysis and priority setting", the most frequently cited sub-step is the identification of the problem. Accordingly, Falzer (2009), emphasized the importance of identifying the decision-making conditions and also the relevant institutions and determined their dependencies as the first steps of EBDM (50). Aas (2012) has also cited the assessment of individuals and problem status and problem-finding as the first steps of EBDM (40). Moreover, the necessity of identifying the existing situation and issues and prioritizing them has been emphasized as the initial steps in most management models such as environmental analysis for strategic planning (51).

In spite of considering the opinions and experience of experts and managers as one of the important sources of evidence for decision-making (49,52-56), many studies, did not mention this sub-step in the EBDM framework. Hence, the present authors added the acquisition of experts' opinions as a sub-step of the first step because of its important role in achieving a comprehensive view of the overall situation.

In the second step, "quantifying the issue and developing a statement", "Developing the conceptual model for the issue" is addressed more than others $(41,43,47,53)$. Also, the fourth sub-step, "Defining the main statement of issue" is added by the authors to complete this step. This is because of that most of the problems in health setting may have a similar value for managers and decision makers and quantifying them can be used as a criterion for more attention or selecting the problem as the main issue to solve.

The third step, "Capacity building and setting objectives", is not seen in any other included studies as a main step in EBDM, however the present authors include this step because without considering the appropriate objectives and preparing necessary capacities and infrastructures, entering to the next steps may become problematic. Moreover, in numerous studies, factors such as knowledge and skills of human resources, training and the availability of the necessary structures and infrastructures have been identified as facilitators of EBDM (57-61). According to this justification, they are included in the present framework as sub-steps of the third step.

Considering the third step and based on the knowledge extracted from the previous studies, the three sub-steps of "understanding context and Building Culture" $(53,54,62)$, "gaining the support and commitment of leaders" $(53,63-65)$, and "identifying the capabilities required by employees and their skills 
weaknesses" (65-68) are the most important sub-steps in this step of EBDM framework. In this regard, Dobrow (2004) has also stated that the two essential components of any EBDM are the evidence and context of its use (38). Furthermore, Isfeedvajani (2018) stated that to overcome barriers and persuade hospital managers and committees to apply evidence-based management and decision-making, first and foremost, creating and promoting a culture of "learning through research" is important (62).

The present findings showed that in the fourth main step, "evidence acquisition and integration", the most important sub-step is "finding the sources for seeking the evidence" $(35,45-47,55,63,65)$. Concerning the sources for the use of evidence in decision-making in HSM, studies have cited numerous sources, most notably scientific and specialized evidence such as research, articles, academic reports, published texts, books, and clinical guidelines (45,69,70). After scientific evidences, using the opinions and experiences of experts, colleagues, and managers $(49,52,55,64)$ as well as the use of census and local level data $(55,64,71)$, and other sources such as financial $(71)$, political $(49,55)$ and evaluations $(55,72)$ data were cited.

\section{Inspecting}

The fifth step of the present framework, "evidence appraising", is emphasized by many literatures; for instance, Pierson (2012) pointed to the use of library services in EBDM (73). In this step, the sub-step of "evaluation and selection of pieces of evidence based on benefits and risks data, feasibility, applicability, and transparency" is cited the most. International and local evidences are confirmed that ignoring these criteria can lead to serious faults in the process of decision and policy making $(74,75)$.

The sixth step, "analysis, synthesis, and interpretation of data", is mentioned in many included studies $(38,41,50,53,76)$. This step emphasized the role of analysis and synthesis of data in the process of generation applied and useful information. It is obvious that the local interpretation according to different contexts may lead to achieve such kind of knowledge that can be used as a basis for local EBDM in HSM.

\section{Implementing}

The third scope consisted of the seventh and eighth steps of EBDM process in HSM. In the seventh step, "developing evidence-based alternatives", the issue of involving stakeholders in decision-making and subsequently, planning to design and implementation of the process and evaluation strategies has been the focus of previous studies $(55,60,76,77)$. Studies by Belay (2009) and Armstrong (2014) have also emphasized the need to use stakeholder and public opinion as well as local and demographic data in decision-making $(55,71)$.

"Pilot-implementation of selected alternatives" is the eighth step of the framework. The key sub-steps of this step is "Pre-implementation and pilot change in practice" $(35,37,46,63)$ that indicates the significance of testing the strategies in a pilot stage as a pre- requisition of implementing the whole alternatives. It is obvious that without attention to the pilot stage, adverse and unpleasant outcomes may occur that their correction process imposes much financial, organizational and human costs on the originations. In addition, a study explained that one of the strategies of the decision-makers to measure the feasibility of the policy options was piloting them which had a higher chance of being approved by the policymakers. Also, pilot implementation in smaller scales has also been recommended in public health in cases of lack of sufficient evidence (78).

\section{Integrating}

This last scope consists of the ninth and tenth steps. The main sub-step of the ninth step, "evaluating alternatives", is to evaluate the implementation process and the resulting outputs. This sub-step after a successful implementation of the pilot can be assuring that the probable outcomes may be achieved and this evaluation will help the decision and policy makers to control the final outcomes. Also, it impacts the whole target program and proposes some correcting plans through an accurate feedback process, too. Pagoto (2007) explained that a facilitator for EBDM would be an efficient and user-friendly system to assess utilization, outcomes, and perceived benefits (61).

Also, the tenth step, "integrating and maintaining change in practice", is not considered as a major step in previous models, too, while it is important to maintain and sustain positive changes in organizational performance. In this regard, Ward (2011) also suggested a number of steps to maintain and sustain the widespread changes in the organization, including increasing the urgency and speed of action, forming a team, getting the right vision, negotiating for buyin, empowerment, short-term success, not giving up and help to make a change stick (41). Finally, the most important sub-steps that can be mentioned in this step are the "dissemination of evidence results to decision makers" and the "integration of changes made to existing standards and performance guidelines". Liang (2012) has also emphasized the importance of translating existing evidence into useful practices as well as disseminating them (53). In addition, the final sub-step, "feedback and feedforward towards the EBDM framework", is explained by the authors to complete the framework.

In addition to what is discussed separately in each of the present framework's scopes and steps, this ten-step framework can give a comprehensive view of a whole model to use evidences for decision-making in HSM. However, it seems that the applicability of the framework in different settings may be assured through future quantitative and qualitative studies. Also, as the other studies confirmed, such a framework has some potential benefits as follows; a deep understanding of improved ability to categorize and select information, engage with customers more closely and pay closer attention to their experiences, learning about critical thinking, improving self-efficacy and cognitive skills (79), gaining knowledge of new topics and applying them, making informed decisions, adapting interventions to community needs, communicating better with colleagues, making rational policy changes, educating others on how to use and apply evidence-based public health information, identifying and comparing costs and benefits of a plan or policy, preparing policy briefing for executives or provincial or local legislators, better funding for programs (80), effective performance, efficiency, transparency and accountability in decision-making and employee empowerment (81).

Considering these potential benefits, it seems that although many organizations specially those situated in under developed and developing countries may not apply such these frameworks in their process of decision and policy making, existing and presenting the framework can help the institutionalizing the concept

Page $10 / 16$ 
of EBDM. For instance, some findings showed that about half and two-thirds of organizations do not regularly collect related data about the use of evidence, and they do not systematically evaluate the usefulness or impact of evidence use on interventions and decisions (82). In addition, the results of a study conducted on healthcare managers at the various levels of one of Iranian largest medical universities showed that the current state of EBDM is not appropriate. This problem is more evident among physicians who have been appointed as managers and who have less managerial and systemic attitudes (83). Such studies, given the shortcomings of current models for EBDM in HSM, have confirmed the necessity of developing a comprehensive framework or model as a practical guide in this field.

In contrast, results of Lavis (2008) study on organizations that supported the use of research evidence in decision-making reported that more than half of the organizations (especially institutions of health technology assessment agencies) may use the evidences in their process of decision making, so applying the present framework for these organizations can be recommended, too.

\section{Limitations}

One of the limitations of the present study was the lack of access to some studies (especially gray literature) related to the subject in question. In addition, most of the existing studies on EBDM were limited to examining and presenting results on influencing, facilitating or hindering factors, or they only mentioned a few components in this area. It should be noted that the framework developed in this study is a conceptual model made by the SSR of studies using the BFF synthesis of existing models; however, it needs validation and localization for making an instrument and using it in countries' health systems.

\section{Conclusions}

It seems that the present framework can be well adapted for those organizations seeking a comprehensive framework to implement EMDM. This framework contains the main four scopes of inquiring, inspecting, implementing and integrating the international and local evidences during 10 steps and the related substeps and tries to present a sequential systematic map to achieve evidence-based decision and policy making specially for under developed and developing countries which mostly suffer from applying update and applied evidences in their decision making process. At the same time, it seems that the present framework tries to synthesize and integrate the fragmented elements of the other models and in this way can be tested by developed countries to improve their EBDM cycle.

\section{Abbreviations}

EBDM; evidence-based decision-making

SSR; Systematic Scoping Review

HSM; Health System Management

BFF; Best-Fit Framework

\section{Declarations}

\section{Ethics approval and consent to participate}

Since at this study a systematic scoping review was done and then the best-fit framework synthesis was used for developing a comprehensive framework for EBDM in HSM, there was no human or animal participant in this study. However, the overall research project related to this manuscript was approved by the medical ethics conceal of the research deputy of shiraz university of medical sciences with approval number IR.SUMS.REC.1396-01-07-14184.

Not applicable

\section{Consent for publication}

Not applicable

\section{Availability of data and material}

All data in a form of data extraction sheets are available from the corresponding author on reasonable request.

\section{Competing interests}

The authors declare that they have no competing interests.

\section{Funding}

As the overall study was an approved research project of shiraz university of medical sciences and was conducted by Mrs. Tahereh Shafaghat as part of the activities required for a Ph.D. degree in health care management field, this study was supported by the shiraz university of medical sciences. This study was sponsored by Shiraz University of Medical Sciences under code (97-

01-07-18586). The funding body was not involved in the design of the study, data collection, analysis, and interpretation, as well as in writing the manuscript. 


\section{Authors' contributions}

PB and TSH designed the study and its overall methodology. BP also edited and finalized the article. TSH searched all the databases and with the help of MRAM retrieved the sources and scanned and screened all the articles in 3 phases. TSH also prepared the draft of the article. MAB and MKRZ contributed to data analysis and synthesis. Also, the study was under consultation and supervision by ZK and MHIN as advisors. All the authors have read and approved the final manuscript.

\section{Acknowledgements}

This research, derived from Proposal No. 96-01-07-14184, was conducted by Mrs. Tahereh Shafaghat as part of the activities required for a Ph.D. degree in health care management at the Shiraz University of Medical Sciences. The authors wish to express their sincere gratitude to the research administration of Shiraz University of Medical Sciences for its financial and administrative support and to the English editorial board of Research Editor institution for improving native English language of this work.

\section{References}

1. Rychetnik L, Bauman A, Laws R, King L, Rissel C, Nutbeam D, et al. Translating research for evidence-based public health: Key concepts and future directions. J Epidemiol Community Health. 2012;66(12):1187-92.

2. Nutbeam DÃ, Boxall A. What influences the transfer of research into health policy and practice? Observations from England and Australia \$. 2008;(May 2007):747-53.

3. Brownson RC, Fielding JE, Maylahn CM. Evidence-Based Public Health: A Fundamental Concept for Public Health Practice. Annu Rev Public Health [Internet]. 2009;30(1):175-201. Available from: http://www.annualreviews.org/doi/10.1146/annurev.publhealth.031308.100134

4. Brownson RC, Gurney JG, Land GH. Evidence-based decision making in public health. J Public Heal Manag Pract [Internet]. 1999 [cited 2018 May 26];5(5):86-97. Available from: https://books.google.com/books?

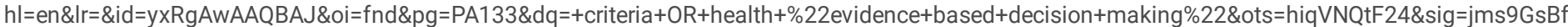

5. McGinnis JM. 'Does Proof Matter? Why Strong Evidence Sometimes Yields Weak Action.' Am J Heal Promot [Internet]. 2001;15(5):391-396. Available from: doi: 10.4278/0890-1171-15.5.391.

6. Majdzadeh R, Yazdizadeh B, Nedjat S, Gholami J, Ahghari S, R. M, et al. Strengthening evidence-based decision-making: Is it possible without improving health system stewardship? Health Policy Plan [Internet]. 2012 Sep 1 [cited 2018 May 15];27(6):499-504. Available from:

https://academic.oup.com/heapol/article-lookup/doi/10.1093/heapol/czr072

7. WHO EIPNET. Using evidence and innovation to strengthen policy and practice. 2008.

8. Orton L, Lloyd-Williams F, Taylor-Robinson D, O'Flaherty M, Capewell S. The use of research evidence in public health decision making processes: Systematic review. PLoS One. 2011;6(7).

9. Sheldon TA. Making evidence synthesis more useful for management and policy-making. J Health Serv Res Policy. 2005;10(1_suppl):1-5.

10. Ellen ME, Léon G, Bouchard G, Lavis JN, Ouimet M, Grimshaw JM. What supports do health system organizations have in place to facilitate evidenceinformed decision-making? A qualitative study. Implement Sci. 2013;8(1).

11. El-Jardali F, Lavis JN, Ataya N, Jamal D, Ammar W, Raouf S. Use of health systems evidence by policymakers in eastern mediterranean countries: Views, practices, and contextual influences. BMC Health Serv Res. 2012;12(1)

12. Ettelt S, Mays N. Health services research in Europe and its use for informing policy. J Health Serv Res Policy [Internet]. 2011 Jul 29 [cited 2019 Jun 29];16(2_suppl):48-60. Available from: http://journals.sagepub.com/doi/10.1258/jhsrp.2011.011004

13. Sutcliffe S. Evidence-Based Policymaking: What is it? How does it work? What relevance for developing countries? 2005.

14. Campbell DM, Redman S, Jorm L, Cooke M, Zwi AB, Rychetnik L. Increasing the use of evidence in health policy: Practice and views of policy makers and researchers. Aust New Zealand Health Policy. 2009;6(1):1-11.

15. WHO. Supporting the Use of Research Evidence (SURE) for Policy in African Health Systems. 2007;(September):1-72.

16. Oxman AD, Lavis JN, Lewin S, Fretheim A. Health Research Policy and Systems 1: What is evidence-informed policymaking? 2009;7:1-7.

17. Armstrong R, Waters E, Dobbins $M$, Anderson L, Moore L, Petticrew M, et al. Knowledge translation strategies to improve the use of evidence in public health decision making in local government: Intervention design and implementation plan. Implement Sci [Internet]. 2013;8(1):1. Available from: https://www.scopus.com/inward/record.uri?eid=2-s2.0-84885076767\&doi=10.1186\%2F1748-5908-8121\&partnerID=40\&md5=dddaf4029205c63877a3e6ecf28f7762

18. Waters E, Armstrong R, Swinburn B, Moore L, Dobbins M, Anderson L, et al. An exploratory cluster randomised controlled trial of knowledge translation strategies to support evidence-informed decision-making in local governments (The KT4LG study). BMC Public Health [Internet]. 2011;11(1):34. Available from: http://www.biomedcentral.com/1471-2458/11/34

19. Imani-Nasab MH, Yazdizadeh B, Salehi M, Seyedin H, Majdzadeh R. Validity and reliability of the Evidence Utilisation in Policymaking Measurement Tool (EUPMT). Heal Res Policy Syst. 2017;15(1):1-11.

20. Health Public Accreditation Board. Public Health Accreditation Board STANDARDS: AN OVERVIEW. 2012;(May 2011).

21. Riley WJ, Bender K, Lownik E. Public health department accreditation implementation: Transforming public health department performance. Am J Public Health. 2012;102(2):237-42. 
22. Liebman JB. Building on Recent Advances in Evidence-Based Policymaking. 2013;(April):36. Available from: http://www.americaachieves.org/9F42769C3A65-4CCB-8466-E7BFD835CFE7/FinalDownload/Downloadld-0AB31816953C7B8AFBD2D15DFD39D5A8/9F42769C-3A65-4CCB-8466-

E7BFD835CFE7/docs/RFA/THP_Liebman.pdf

23. Jacobs J a, Jones E, Gabella B a, Spring B, Brownson C. Tools for Implementing an Evidence-Based Approach in Public Health Practice. Prev Chronic Dis [Internet]. 2012;9(1):1-9. Available from: http://dx.doi.org/10.5888/pcd9.110324

24. Kothari A, Edwards N, Hamel N, Judd M. Is research working for you? validating a tool to examine the capacity of health organizations to use research. Implement Sci. 2009;4(1):1-9.

25. Oxman AD, Bjørndal A, Becerra-Posada F, Gibson M, Block MAG, Haines A, et al. A framework for mandatory impact evaluation to ensure well informed public policy decisions. Lancet [Internet]. 2010;375(9712):427-31. Available from: http://dx.doi.org/10.1016/S0140-6736(09)61251-4

26. Oxman AD, Vandvik PO, Lavis JN, Fretheim A, Lewin S. SUPPORT Tools for evidence-informed health Policymaking (STP) 2: Improving how your organisation support the use of research evidence to inform policymaking. Chinese J Evidence-Based Med. 2010;10(3):247-54.

27. The Joanna Briggs Institute. The Joanna Briggs Institute Reviewers ' Manual 2015 Methodology for JBI Scoping Reviews. Joanna Briggs Institute,The Univ Adelaide. 2015;

28. Grant MJ, Booth A. A typology of reviews: an analysis of 14 review types and associated methodologies. Health Info Libr J [Internet]. 2009;26(2):91-108. Available from: http://www.ncbi.nlm.nih.gov/pubmed/19490148

29. Arksey H, Malley LO. SCOPING STUDIES: TOWARDS A METHODOLOGICAL FRAMEWORK. 2005;19-32.

30. Brien SE, Lorenzetti DL, Lewis S, Kennedy J, Ghali WA. Overview of a formal scoping review on health system report cards. Implement Sci. 2010;5(1):112.

31. Carroll C, Booth A, Cooper K. A worked example of " best fit " framework synthesis: A systematic review of views concerning the taking of some potential chemopreventive agents. 2011;

32. Carroll C, Booth A, Leaviss J, Rick J. " Best fit " framework synthesis: refining the method. BMC Med Res Methodol [Internet]. 2013;13(1):1. Available from: BMC Medical Research Methodology

33. Dixon-woods M. Using framework-based synthesis for conducting reviews of qualitative studies. BMC Med [Internet]. 2011;9(1):39. Available from: http://www.biomedcentral.com/1741-7015/9/39

34. Barnett-page E, Thomas J. Methods for the synthesis of qualitative research: a critical review. BMC Med Res Methodol. $2009 ; 1-26$.

35. Rosswurm MA, Larrabee JH. A Model for Change to Evidence-Based Practice. J Nurs Scholarsh. 1999;31(4):317-22.

36. Brownson RC, Gurney JG, Land GH. Evidence-Based Decision Making in Public Health. J Public Heal Manag Pract [Internet]. 1999;5(5):86-97. Available from: https://books.google.com/books?

$\mathrm{hl}=$ en\&lr=\&id=yxRgAwAAQBAJ\&oi=fnd\&pg=PA133\&dq=+criteria+OR+health+\%22evidence+based+decision+making\%22\&ots=hiqVNQtF24\&sig=jms9GsBf

37. Titler MG. The lowa Model of evidence-based practice to promote quality care. 2001.

38. Dobrow MJ, Goel V, Upshur REG. Evidence-based health policy: context and utilisation. Soc Sci Med [Internet]. 2004;58(1):207-17. Available from: http://www.sciencedirect.com/science/article/pii/S0277953603001667

39. Kohatsu ND, Robinson JG, Torner JC. Evidence-based public health: An evolving concept. Am J Prev Med. 2004;27(5):417-21.

40. Aas RW, Alexanderson K. Challenging Evidence-based Decision-making: A Hypothetical Case Study about Return to Work. Occup Ther Int [Internet]. 2012 Mar [cited 2018 May 28];19(1):28-44. Available from: http://doi.wiley.com/10.1002/oti.326

41. Ward M. Evidence-informed decision making in a public health setting. Healthc Manag Forum. 2011;24(1 SUPPL.).

42. Champagne F, Lemieux-Charles L, Duranceau M-F, MacKean G, Reay T. Organizational impact of evidence-informed decision making training initiatives: A case study comparison of two approaches. Implement Sci [Internet]. 2014;9(1). Available from: https://www.scopus.com/inward/record.uri?eid=2-s2.084900004312\&doi=10.1186\%2F1748-5908-9-53\&partnerID=40\&md5=df5573f17e19ef002d67cf669059aef4

43. Wright AL, Zammuto RF, Liesch PW, Middleton S, Hibbert P, Burke J, et al. Evidence-based Management in Practice: Opening up the Decision Process, Decision-maker and Context. Br J Manag [Internet]. 2016;27(1):161-78. Available from: http://doi.wiley.com/10.1111/1467-8551.12123

44. Stamatakis KA, Ferreira Hino AA, Allen P, McQueen A, Jacob RR, Baker EA, et al. Results from a psychometric assessment of a new tool for measuring evidence-based decision making in public health organizations. Eval Program Plann [Internet]. 2017 Feb [cited 2018 May 16];60:17-23. Available from: http://linkinghub.elsevier.com/retrieve/pii/S014971891630009X

45. Harris C, Allen K, Waller C, Dyer T, Brooke V, Garrubba M, et al. Sustainability in Health care by Allocating Resources Effectively (SHARE) 7: supporting staff in evidence-based decision-making, implementation and evaluation in a local healthcare setting. BMC Health Serv Res [Internet]. 2017 Dec 21 [cited 2018 May 19];17(1):430. Available from: http://bmchealthservres.biomedcentral.com/articles/10.1186/s12913-017-2388-8

46. Harris C, Garrubba M, Melder A, Voutier C, Waller C, King R, et al. Sustainability in Health care by Allocating Resources Effectively (SHARE) 8: Developing, implementing and evaluating an evidence dissemination service in a local healthcare setting. BMC Health Serv Res [Internet]. 2018;18(1). Available from: https://www.scopus.com/inward/record.uri?eid=2-s2.0-85042873576\&doi=10.1186\%2Fs12913-018-2932-

1\&partnerlD=40\&md5=2daa5bbd3ccddf299f7b9d527b6105af

47. Yost J, Dobbins M, Traynor R, DeCorby K, Workentine S, Greco L. Tools to support evidence-informed public health decision making. BMC Public Health [Internet]. 2014 Dec 18 [cited 2018 May 28];14(1):728. Available from: http://bmcpublichealth.biomedcentral.com/articles/10.1186/1471-2458-14-728

48. Wahabi HA, Siddiqui AR, Mohamed AG, Al-hazmi AM, Zakaria N, Al-ansary LA. Evidence based decision making in public health: capacity building for public health students at King Saud University in Riyadh. Biomed Res Int [Internet]. 2015 [cited 2018 May 26];2015:1-8. Available from:

https://www.hindawi.com/journals/bmri/2015/576953/abs/

Page $13 / 16$ 
49. Janati A, Hasanpoor E, Hajebrahimi S, Sadeghi- H, Khezri A. An Evidence-Based Framework for Evidence-Based Management in Healthcare Organizations: A Delphi Study. Ethiop J Heal Sci. 2018;28(3):305-14.

50. Falzer PR, Garman MD. A conditional model of evidence-based decision making. J Eval Clin Pract [Internet]. 2009 Dec [cited 2018 May 19];15(6):1142-51. Available from: http://doi.wiley.com/10.1111/j.1365-2753.2009.01315.x

51. Ginter PM, Duncan WJ, Swayne LE. Strategic management of health care organizations. seventh. Jossey-Bass imprint; 2013.

52. Humphries S, Stafinski T, Mumtaz Z, Menon D. Barriers and facilitators to evidence-use in program management: a systematic review of the literature. BMC Health Serv Res [Internet]. 2014 Dec 14 [cited 2018 May 19];14(1):171. Available from: http://bmchealthservres.biomedcentral.com/articles/10.1186/1472-6963-14-171

53. Liang Z, Howard PF, Leggat SG, Murphy G. A framework to improve evidence-informed decision-making in health service management. Aust Heal Rev [Internet]. 2012;36(3):284-9. Available from: https://www.scopus.com/inward/record.uri?eid=2-s2.0-

84865450745\&doi=10.1071\%2FAH11051\&partnerID=40\&md5=c42d56774cd486b8df8a5e4afec33a6a

54. Kazman Kohn M, Berta W, Langley A, Davis D. Evidence-Based Decision Making in Health Care Settings: From Theory to Practice. In 2011 [cited 2018 May 26]. p. 215-34. Available from: http://www.emeraldinsight.com/doi/10.1108/S1474-8231\%282011\%290000011012

55. Armstrong R, Waters E, Moore L, Dobbins M, Pettman T, Burns C, et al. Understanding evidence: a statewide survey to explore evidence-informed public health decision-making in a local government setting. Implement Sci [Internet]. 2014;9(1):188. Available from:

http://implementationscience.biomedcentral.com/articles/10.1186/s13012-014-0188-7

56. McDiarmid M, Sandra K, Binns M. Evidence-based administrative decision making and the Ontario hospital CEO: information needs, seeking behaviour, and access to sources. JCHLA / JABSC [Internet]. 2007 [cited 2018 May 28];28:63-72. Available from:

https://ejournals.library.ualberta.ca/index.php/jchla/article/viewFile/24060/17884

57. Brownson RC, Allen P, Duggan K, Stamatakis KA, Erwin PC. Fostering more-effective public health by identifying administrative evidence-based practices: A review of the literature. Am J Prev Med [Internet]. 2012;43(3):309-19. Available from: https://www.scopus.com/inward/record.uri?eid=2-s2.0-

84865688888\&doi=10.1016\%2Fj.amepre.2012.06.006\&partnerID=40\&md5=a843f04e58b619ab9355a98bbfeef51a

58. Moussata CO. Evidence-Based Management and its Influence on the Practices of Senior Leaders of Hospitals in the Denver Metropolitan Area [Internet]. ProQuest Dissertations and Theses. [Ann Arbor]: Colorado Technical University; 2017 [cited 2018 May 19]. Available from:

https://search.proquest.com/docview/1967189422?accountid=41313

59. Ward M, Mowat D. Creating an organizational culture for evidence-informed decision making. Healthc Manag Forum [Internet]. 2012;25(3):146-50. Available from: https://www.scopus.com/inward/record.uri?eid=2-s2.084867778644\&doi=10.1016\%2Fj.hcmf.2012.07.005\&partnerID=40\&md5=42f06b7236a4a1cd6a4739c7e1900764

60. Sosnowy CD, Weiss LJ, Maylahn CM, Pirani SJ, Katagiri NJ. Factors affecting evidence-based decision making in local health departments. Am J Prev Med [Internet]. 2013 Dec [cited 2018 May 19];45(6):763-8. Available from: http://ovidsp.ovid.com/ovidweb.cgi?

$\mathrm{T}=\mathrm{JS} \& C S C=Y \& N E W S=N \& P A G E=$ fulltext\&D=medI\&AN=24237920 http://sfx.scholarsportal.info/mcmaster? sid=OVID:medline\&id=pmid:24237920\&id=doi:10.1016\%2Fj.amepre.2013.08.004\&issn=0749-3797\&isbn=\&volume=45\&issue=6\&spage=763\&pages=76

61. Pagoto SL, Spring B, Coups EJ, Mulvaney S. Barriers and Facilitators of Evidence-Based Practice Perceived by Behavioral Science Health Professionals. 2007;63(7):695-705.

62. Isfeedvajani MS. Evidence-Based Management and its Application in the Hospital Management Process. Hosp Pract Res [Internet]. 2018 [cited 2018 May 28];3(2):35-6. Available from: http://jhpr.ir/article_60533_8313dd6afa580ef2afa689e6984c8844.pdf

63. Stamatakis KA, Ferreira Hino AA, Allen P, McQueen A, Jacob RR, Baker EA, et al. Results from a psychometric assessment of a new tool for measuring evidence-based decision making in public health organizations. Eval Program Plann [Internet]. 2017;60:17-23. Available from: http://linkinghub.elsevier.com/retrieve/pii/S014971891630009X

64. Harris C, Allen K, Waller C, Green S, King R, Ramsey W, et al. Sustainability in Health care by Allocating Resources Effectively (SHARE) 5: developing a model for evidence-driven resource allocation in a local healthcare setting. BMC Health Serv Res. 2017;17(1):1-18.

65. Harris C, Turner T, Wilkinson F. SEAchange: guide to pragmatic evidence-based approach to sustainable, effective and appropriate change in health services. 2015;(April 2016).

66. Aas RW, Alexanderson K. Challenging evidence-based decision-making: A hypothetical case study about return to work. Occup Ther Int [Internet]. 2012 Mar [cited 2018 May 28];19(1):28-44. Available from: http://doi.wiley.com/10.1002/oti.326

67. Dobbins M, Jack S, Thomas H, Kothari A. Public health decision-makers' informational needs and preferences for receiving research evidence. WORLDVIEWS EVIDENCE-BASED Nurs. 2007;4(3):156-63.

68. Pappaioanou M, Malison M, Wilkins K, Otto B, Goodman RA, Churchill RE, et al. Strengthening capacity in developing countries for evidence-based public health:: The data for decision-making project. Soc Sci Med. 2003;57(10):1925-37.

69. Janati A, Hasanpoor E, Hajebrahimi S, Sadeghi-Bazargani H. Health care managers' perspectives on the sources of evidence in evidence-based hospital management: A qualitative study in Iran. Ethiop J Health Sci [Internet]. 2017;27(6):659. Available from:

https://www.ajol.info/index.php/ejhs/article/view/162555

70. Spiri WC, Kurcgant P, Pereira MV. Perception Of Nursing Middle Managers About The Evidence-Based Management. Int Arch Med [Internet]. 2017;10(February):11. Available from: http://imedicalsociety.org/ojs/index.php/iam/article/view/2311

71. Belay T, Mbuya N, Rajan V. Data utilization and evidence-based decision making in the health sector: survey of three Indian states. 2009 [cited 2018 May 26]; Available from: https://openknowledge.worldbank.org/handle/10986/3161

Page 14/16 
72. Niedzwiedzka BM. Barriers to evidence-based decision making among Polish healthcare managers. Heal Serv Manag Res [Internet]. 2003 May 21 [cited 2018 May 19];16(2):106-15. Available from: http://journals.sagepub.com/doi/10.1258/095148403321591429

73. Peirson L, Ciliska D, Dobbins M, Mowat D. Building capacity for evidence informed decision making in public health: A case study of organizational change. BMC Public Health [Internet]. 2012;12(1):137. Available from: https://www.scopus.com/inward/record.uri?eid=2-s2.0-

84857132983\&doi=10.1186\%2F1471-2458-12-137\&partnerID=40\&md5=68e18844316881fb3f2662477825d441

74. Buffett C, Ciliska D, Thomas H. Can I Use This Evidence in my Program Decision? Assessing Applicability and Transferability of Evidence. 2007; (November):1-22.

75. Buffet C, Ciliska D, Thomas H. It worked there. Will it work here? a tool for assessing Applicability and Transferability of Evidence (A: When considering starting a new program). Hamilton, Natl Collab Cent Methods Tools. 2011;(905):1-2.

76. Li Y, Kong N, Lawley M, Weiss L, Pagán JA. Advancing the Use of Evidence-Based Decision-Making in Local Health Departments With Systems Science Methodologies. Am J Public Health [Internet]. 2015;105(S2):S217-S222. Available from: http://ajph.aphapublications.org/doi/10.2105/AJPH.2014.302077

77. Brownson RC. Practice-Research Partnerships and Mentoring to Foster Evidence-Based Decision Making. Prev Chronic Dis. $2014 ; 11$.

78. Imani-Nasab MH, Seyedin H, Yazdizadeh B, Majdzadeh R. A Qualitative Assessment of the Evidence Utilization for Health Policy-Making on the Basis of SUPPORT Tools in a Developing Country. Int J Heal policy Manag. 2017 Jan;6(8):457-65.

79. Baarends E, Van der Klink M, Thomas A. An exploratory study on the teaching of evidence-based decision making. Open J Occup Ther [Internet]. 2017 Jul 1 [cited 2018 May 20];5(3):1-20. Available from: https://scholarworks.wmich.edu/ojot/vol5/iss3/8

80. Yarber L, Brownson CA, Jacob RR, Baker EA, Jones E, Baumann C, et al. Evaluating a train-the-trainer approach for improving capacity for evidence-based decision making in public health. BMC Health Serv Res [Internet]. 2015 Jun 12 [cited 2018 May 26];15(1):547. Available from:

http://bmchealthservres.biomedcentral.com/articles/10.1186/s12913-015-1224-2

81. Trinder L. A Critical Appraisal of Evidence-Based Practice. In: Royal United Services Institution Journal. 2000. p. 154-63.

82. Lavis JN, Paulsen EJ, Oxman AD, Moynihan R. Evidence-informed health policy 2-Survey of organizations that support the use of research evidence. Implement Sci. 2008;3.

83. Bastani P, Kavosi Z, Alipoori S, Imani-Nasab MH. Evidence- based Policy and Decision-Making among Health Managers: A Case of Shiraz Univer- sity of Medical Sciences. GMJ. 2017;6(1):30-8.

\section{Figures}

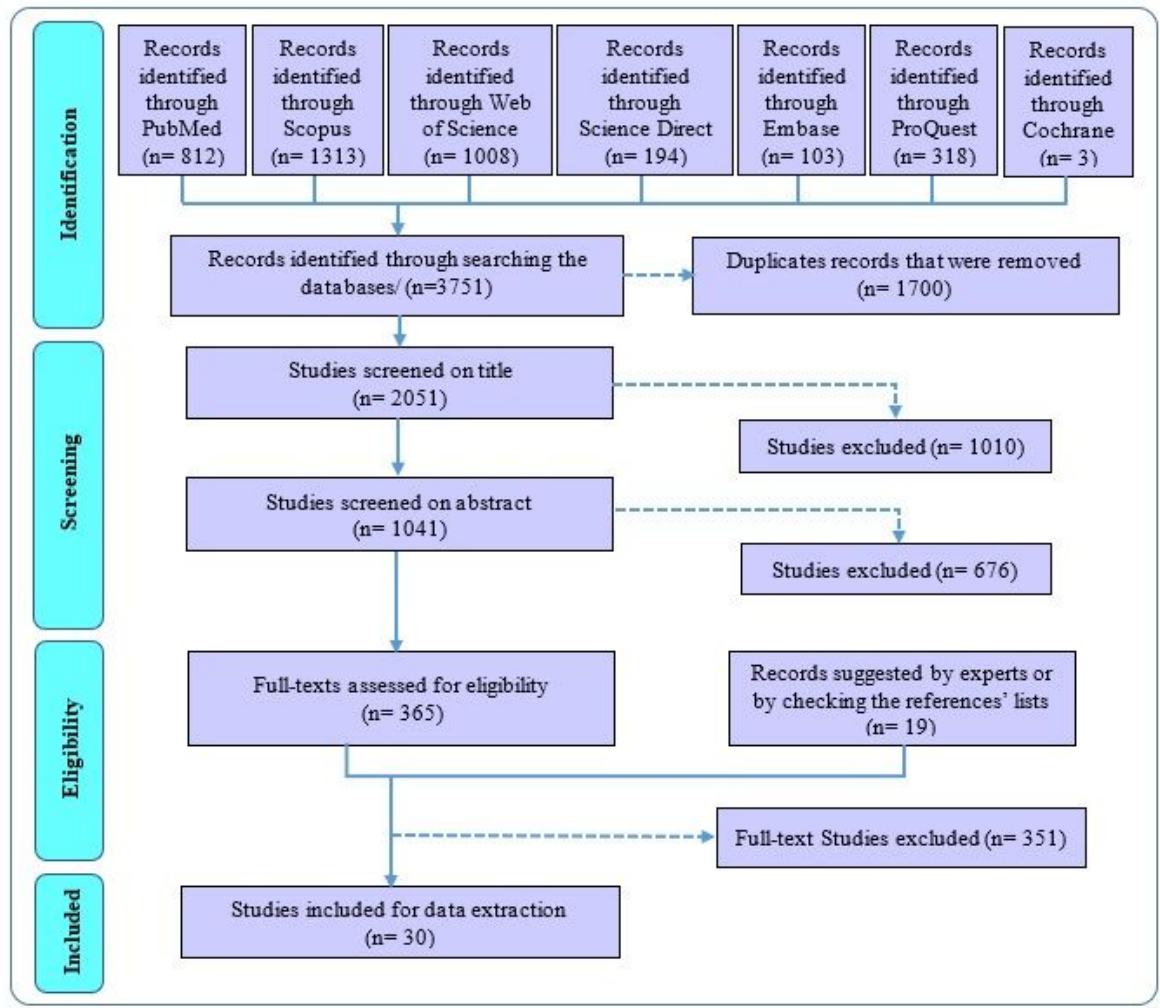

Figure 1

PRISMA Flow diagram for article selection 


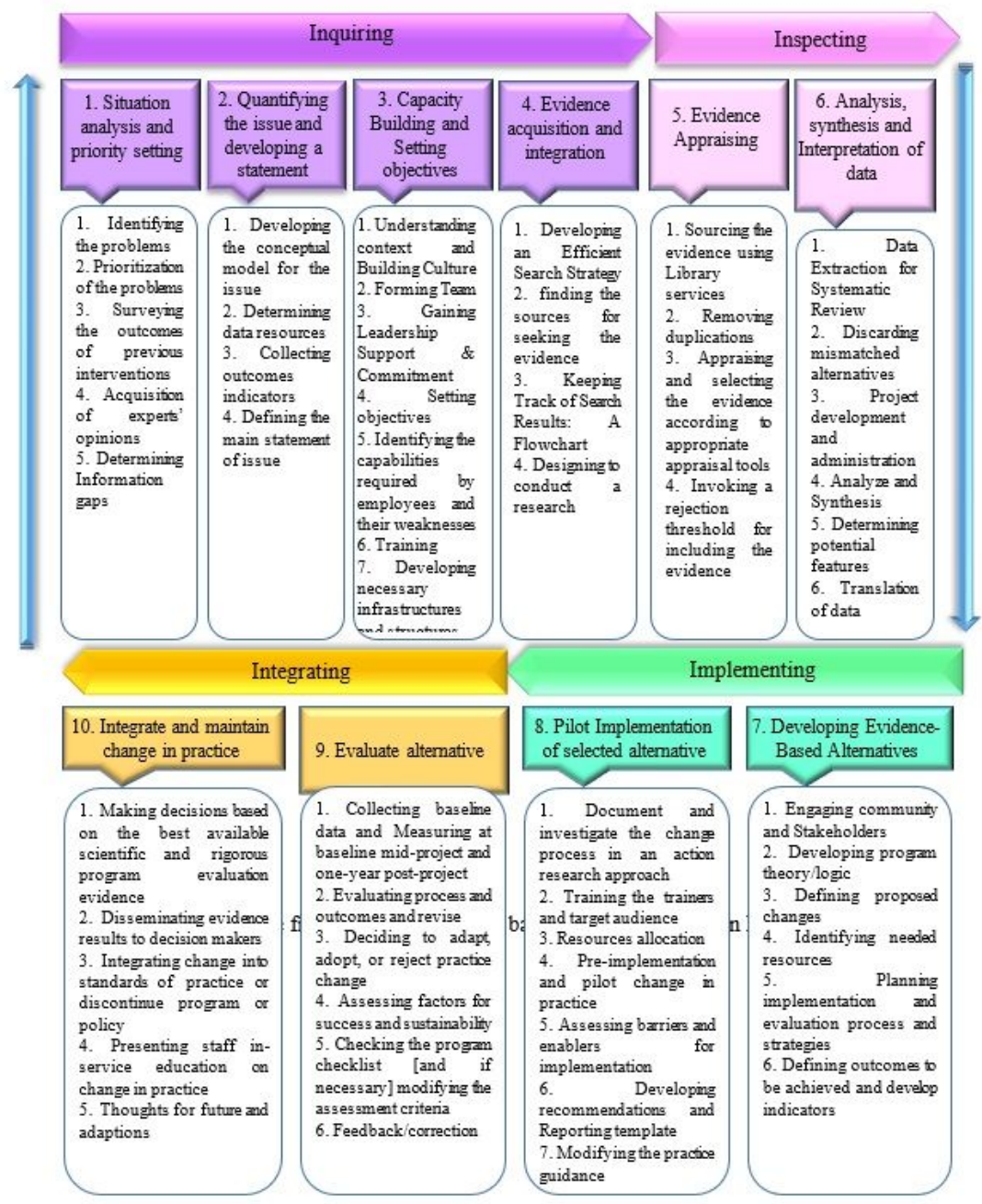

Figure 2

The framework of evidence based decision making in HSM

\section{Supplementary Files}

This is a list of supplementary files associated with this preprint. Click to download.

- PRISMAScRFillableChecklist10Sept20191.pdf 